\title{
Influences of anatomical differences on gender-specific book-carrying behavior
}

\author{
JUDITH D. SCHEMAN, JOAN S. LOCKARD, and BRUCE L. MEHLER \\ University of Washington, Seattle, Washington 98195
}

\begin{abstract}
Book-carrying styles of 1,133 school-age children (kindergarten through high school) were observed, and anatomical measurements (hips, waist, and underarm) of the space between the trunk and fall line of the arm in 735 of the students were recorded. With the exception of handedness, the results replicated those of earlier studies of sexual differences in bookcarrying styles and implicated the protrusion of female hips as instrumental in this phenomenon.
\end{abstract}

Hanaway and Burghardt (1976), Jenni and Jenni (1976), and Spottswood and Burghardt (Note 1) demonstrated sexual dimorphic book-carrying styles in college students. A preliminary study by Scheman (Note 2) replicated the findings (with the exception of handedness) of these investigators. The results indicated that the adult male carries with his arm extended and to his side, grasping the books with his hand and holding them parallel to both his arm and body (e.g., Figure 1F). However, adult females carry above the hips and with the arm forming a right angle at the elbow; the books are supported against the front of the body, typically on the hip (e.g., Figure 1E).

Hanaway and Burghardt (1976) and Jenni and Jenni (1976) also established when in the development of the child the differences in book-carrying styles occur. They found that after age 6 years, males and females become relatively locked into the adult genderspecific style of carry. The present study addresses the replicability of these findings in a relatively liberal community and employs a more controlled sampling procedure than was used in the previous studies. With respect to the former, some of the cultural influences on this phenomenon may be manifested in the chosen subject population. With respect to the latter, the possibility of experimenter bias in subject selection is eliminated by observing the total population of the given subgroup; in other words, every child in the specific school classes was included in the study.

Previous studies also discussed the possible role of anatomical differences in males and females which may contribute to the differences in book-carrying styles. The present study attempted to quantify to what extent morphological differences affect the prevalence of the different styles. Not only was the subject's style of book-carrying noted, but hip, waist, and underarm measurements were also recorded. An

The authors wish to express their appreciation to the Union Free School Districts in Long Island, New York for permitting the studies to take place in their schools. Reprint requests to Joan S. Lockard, University of Washington (RI-20), Seattle, Washington 98195. attempt was made to develop a measure of "figure" that would most adequately account for the differences in style. The specific hypothesis tested was that women with hips that extend past the comfortable fall line of the arm along the side of the body will not show the side carry typically seen in males. The crux of the question was whether or not the physical protrusion of the hip is a limiting factor in the manner in which women carry their books. It was assumed that the style of book carry is a product of both physical and

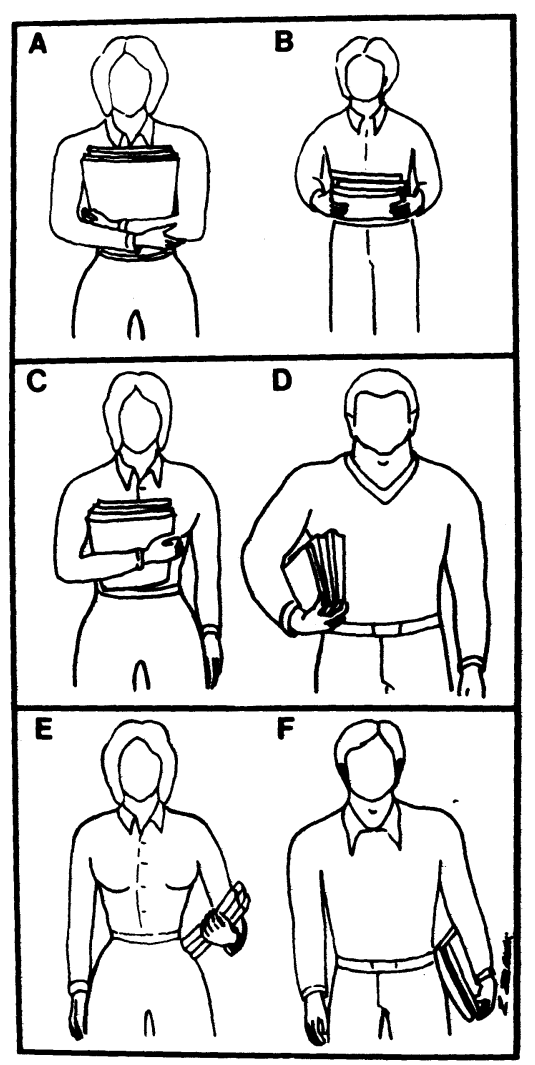

Figure 1. Book-carrying styles. $A$ and $B=$ front, both hands; $C$ and $D=$ front, one hand, female and male, respectively; $E=$ top, typical female style; $F$ = side, typical male style. 
social factors, and is not simply either a cultural phenomenon or a biochemical one related to the hormonal differences in males and females.

\section{METHOD}

\section{Subject Selection and Environmental Setting}

Book-carrying styles and measurements were recorded for 735 school-age children from two school districts in Long Island, New York. The children ranged from kindergarten through seniors in high school. In addition, the book-carrying style of 398 males in junior and senior high school were observed but were not measured in terms of hip, waist, and underarm dimensions.

The total number of subjects in the elementary school was 246, 124 males and 122 females. In the junior high, a total of 158 students was measured, 55 males and 103 females; 135 males were observed for book-carrying style but were not measured. In the high school, there were 63 students, 14 males and 49 females; the carrying styles of 246 males were recorded but they were not measured.

Kindergarten and elementary school children were observed as they carried books from their classes to a room where they were measured. These students were instructed to carry a hard-cover notebook, a workbook, and a text to the room where they waited to be measured. They were observed carrying their books a distance of approximately $6 \mathrm{~m}$ to a desk where they were then measured. All subjects were measured.

The junior and senior high school students' styles were recorded as they walked to gym class, and the students were measured after they changed into their uniforms. They were observed as they walked down a corridor approximately $10 \mathrm{~m}$ in length, after which they were handed an identification card to match with their subsequent anatomical measurements. The book-carrying styles of the unmeasured males were noted during the 5-min interval between classes.

\section{Data Recording}

The subjects were observed for book-carry style and later measured with an artist's caliper, which was applied to a metric rule for transformation into millimeters. Numbers 1-7 were used to describe the styles employed in the book carry. Styles 1 and 2 were the top-left and top-right carry, respectively, of the typical female carry with the books resting on the hip and the forearm angled out (e.g., Figure 1E). Styles 3 and 4 were the left-side and right-side carry, respectively, of the typical male carry described as arm down at the side, books rested along the leg and side of the hip, with hand hooked around the books (e.g., Figure 1F). Styles 5 and 6 were the front-left and front-right carry, respectively; in these styles the books are flat against the chest and both the books and the forearm are parallel to the trunk (e.g., Figure 1C for females and Figure 1D for males). In Style 7 both arms are used in holding the books at or above the waist, either at an angle to the trunk (e.g., Figure 1B) or flat (e.g., Figure 1A). Number 8 was used to designate those subjects not carrying books, a common occurrence among junior and senior high school males.

\section{Observer Reliability}

Whereas there was one observer of the elementary school children, there was an additional observer in collecting the data on junior and senior high school students. Reliability checks were made periodically and agreement between the two observers was $100 \%$.

\section{RESULTS}

Since there were no significant differences $(p>.05)$ between the side (i.e., right or left) on which the books were carried by males and females, the subsequent analyses were conducted on the pooled data. Figure 2 depicts the book-carrying style of males and females grouped into elementary, junior high, and high school levels. Style of carry differed significantly by sex and by age (school level by style-female: $\chi^{2}=62.09$, $\mathrm{df}=6, \mathrm{p}<.0001 ;$ male: $\chi^{2}=27.04, \mathrm{df}=4, \mathrm{p}<.0001$ ) and there was a significant interaction between the two factors (sex by style: $\chi^{2}=139.67, \mathrm{df}=3$, $\mathrm{p}<.0001$; age by style: $\chi^{2}=142.95, \mathrm{df}=42, \mathrm{p}<.0001$ ). Kindergarten children did not show a statistically significant difference by sex in book-carrying style $(\mathrm{p}>.05)$. The boys and girls carried, respectively, $62 \%$ and $40 \%$ on the side, $15 \%$ and $33 \%$ in the front, $23 \%$ and $27 \%$ with both hands, $0 \%$ of top carry for both males and females. Trends in carrying behavior began to appear after age 5 years, with males shifting predominantly to the side carry and females shifting away from it, first to the both-arm carry and later to a greater use of the front and top carries (see Figure 1).
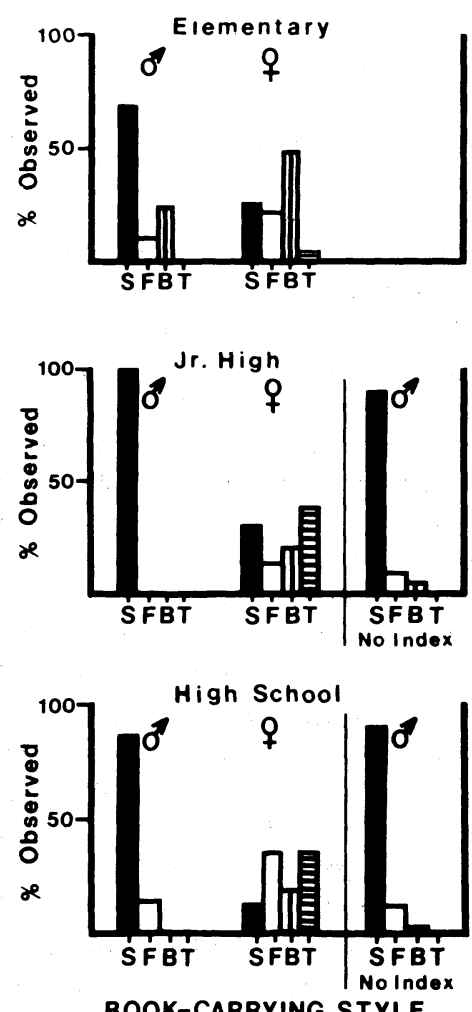

Figure 2. Percentage of each sex displaying the particular style of carry as depicted in Figure $1 . S=$ side, $F=$ front, $B=$ both, and $T=$ top. No index $=$ males with no anatomical measurements taken. 
In order to examine the degree to which physical characteristics could account for the observed styles of carry, several anatomical indexes were computed using the measurements of the hips, waist, and underarms. The index value obtained-employing the formula $[($ hip - underarm $)+($ hip - waist $)]=$ mean "X area" in millimeters-produced the best differentiation between styles of carry. This index of relative protrusion of the hip from the rest of the body conformed well with the frequency of side carry. Table 1 presents the mean values for this index by sex, school level, and style. Regardless of sex, high school men and women who used the side carry tended to have smaller hip-protrusion indexes than those who used other styles of carry (mean $\mathrm{X}$ area $=8.9$ vs. an average of $11.2 ; \mathrm{p}<.05)$. The mean $X$ area $(8.9)$ was identical for both high school men and women who carried on the side. This relationship between a small protrusion index and side carry breaks down when the anaiysis includes individuals younger than high school age.

\section{DISCUSSION}

Results of the present study replicated, in a relatively liberal population using less biased sampling techniques, the differences in style of book carry reported by Hanaway and Burghardt (1976) and Jenni and Jenni (1976). Moreover, it was found that the index of relative hip protrusion ( $X$ area) partitioned styles of carrying books in the high school population. There were, however, individuals who had a large $X$ area (i.e., corresponding to a protrusion of the hip from either the waist or underarm or both) who carried on the side. This observation was particularly evident in the female junior high school population.

Both book-carrying styles, as typified by the high school population, appeared to correspond to the mean morphological

Table 1

An Anatomical Index (X Area) of the Space Between the Trunk and the Fall Line of the Arm. $X$ area $=$ [(hip - underarm) + (hip - waist)] in millimeters.

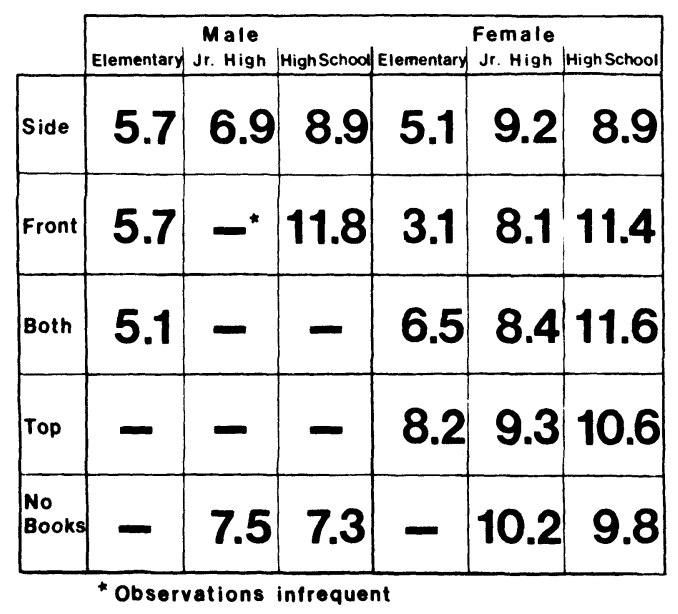

differences in $X$ area between females and males. Males carry on the side because there is an available space there. The arms extend out past their hips since their chests are usually larger than their waists and hips. There is no platform formed by the protrusion of the hips on which to rest books. Females' hips extend out past their chests and/or waists. In effect, the hip in females fills the side space that males fill with their books. [No evidence in either the literature or through personal communication with colleagues could be found for the elbow extension differences in males and females alluded to in Jenni and Jenni (1976).]

The style of carry employed by children and teenagers who do not conform to the average, or "model," adult male or female "figure" appears to mimic or model the genderappropriate behavior. This appears to be mostly true of females who carry in the "female" style before their figure mandates such a carry. The "figure" of males develops more slowly and consistently than that of the females. Significant differences in relative hip protrusion between males of different ages are found only when the boys are grouped by school types; in other words, the variance in $\mathrm{X}$ area between ages of males is greater than the variance within ages of males. Consistent with this outcome, the style of carry for males is also more conservative, changing and varying less often. However, females grow in spurts, changing more dramatically in "figure" from year to year. Compatible with these observations, female styles are also more varied and influenced by physical change.

As with any behavior observed in public, the social context in which it is observed must be taken into account. School children are inevitably under pressure to conform to the school norms. Hanaway and Burghardt (1976) suggest that the social pressures and censures against sex-inappropriate behavior are stronger for males than for females. Although the norm for any given school might appear to be asocial when compared to a population of schools, their explanation appears viable for the data on junior high school students in the present study. The book-carrying styles of males were sex appropriate and corresponded with the physical-measurement index. However, the female styles varied considerably and did not conform completely to the index values. It was noted (although not systematically) that many of the other behaviors displayed by these females were also asocial. The current cultural pressures on females in this relatively liberal locale to become more independent could result in their "going out of their way" to carry in the male style if this style were the asocial norm for this particular school or area. Such cultural influence may also account, in part, for nonverification of the left-, right-side distinction in book carry between females and males, respectively, found in earlier studies. Also, there was an unusually high percentage $(15 \%)$ of left-handed females, in terms of their writing hand, in this population, which could have contributed additional variance to the data. The percentage usually quoted is less than $10 \%$ and sometimes as low as $3 \%$ (e.g., Hecaen \& de Ajuriaguerra, 1964).

Although it is possible that females may employ the top carry, in part, to protect their breasts, there were many females in both high school and junior high school carrying on the side without any regard to protecting their breasts from either physical or social harm. This observation was most obvious in the junior high school population, where one would predict this "protection" would be most necessary.

Once again, it appears that the explanation of a behavior in strictly a "nature" or "nurture" argument is insufficient and that an interaction of biological, morphological, and social pressures must be considered. However, in the present study it may be valid to conclude that adult book-carrying behavior is a function of the morphological differences in the availability of space between the arm and hip of females, and that this functional pressure has become overlaid with social-sexual connotations. 


\section{REFERENCE NOTES}

1. Spottswood. P.. \& Burghardt. G. M. The effects of sex. book weight, and grip strength on book-carrying styles. Unpublished manuscript. University of Tennessee, 1975.

2. Scheman. J. D. The appearance of differences in book carning behavior as a function of the hip appendage in women. Unpublished manuscript. University of Washington, 1976.

\section{REFERENCES}

Hanaway. T. P.. \& Burghardt. G. M. The development of sexually dimorphic book-carrying behavior. Bulletin of the Ps.richonomic Society. 1976. 7. 267-270.

Hecaen. H.. \& De Ajuriaguerra, J. Left-handedness manual superiority and cerebral dominance. New York: Grune \& Stratton, 1964

JenNi. D. A.. \& Jenni. M. A. Carrying behavior in humans: Analysis of sex differences. Science. 1976, 194. 859-860.

(Received for publication September 19. 1977.) 